\title{
Comprehensive effects of exogenous salicylic acid and light on chlorophyll fluorescence parameters and photosynthetic oxygen evolution in Ulva prolifera
}

\author{
P.L. ZHUO ${ }^{*, * *}$, Y.H. LI ${ }^{*, * *+,}$ J.L. ZHONG ${ }^{*, * *}$, M.S. ZHENG ${ }^{*, * *}$, W.R. ZHU ${ }^{* * *}$, and N.J. XU ${ }^{*, * *,+}$ \\ School of Marine Sciences, Ningbo University, Ningbo 315211, China* \\ Key Laboratory of Applied Marine Biotechnology of Ministry of Education, Ningbo 315211, China** \\ Xiangshan Xuwen Seaweed Development Co. Ltd, Ningbo 315000, China ${ }^{* * *}$
}

\begin{abstract}
Ulva prolifera is one of the causative species of green tides. Salicylic acid (SA) alleviated the high-temperature damage by up-regulating a portion of antioxidant-related proteins, however, little is understood regarding the impacts of SA under high light in this species. In order to study the regulation effects of SA on U. prolifera under different light conditions, we grew this species under three SA concentrations $\left(0,2.5,5.0 \mu \mathrm{g} \mathrm{mL} \mathrm{mL}^{-1}\right)$ and three light levels [high light (HL): 400 $\mu \mathrm{mol}\left(\right.$ photon) $\mathrm{m}^{-2} \mathrm{~s}^{-1}$, medium light (ML): $160 \mu \mathrm{mol}\left(\right.$ photon) $\mathrm{m}^{-2} \mathrm{~s}^{-1}$, and low light (LL): $70 \mu \mathrm{mol}\left(\right.$ photon) $\mathrm{m}^{-2} \mathrm{~s}^{-1}$. After $3 \mathrm{~d}$, the growth, chlorophyll fluorescence parameters, photosynthetic oxygen rate production, and superoxide dismutase (SOD) activity of $U$. prolifera were investigated. We found that: (1) The relative growth rate (RGR) of $U$. prolifera increased with the increase of light, no matter if with or without SA; under the three light levels, the highest RGR was observed in the presence of $2.5 \mu \mathrm{g}(\mathrm{SA}) \mathrm{mL}^{-1}$. (2) U. prolifera grown under HL conditions showed the highest values in nonphotochemical quenching and total content of cartenoids. (3) Under three light levels, the dark respiration rate, the net, maximal, and gross photosynthetic oxygen rate significantly decreased by SA. (4) The highest value of SOD activity was observed under LL in the presence of SA $\left(5.0 \mu \mathrm{g} \mathrm{mL}^{-1}\right)$. In conclusion, the effects of light on the physiology in $U$. prolifera could be mediated by SA in a concentration-dependent manner.
\end{abstract}

Additional key words: light intensity; photosynthesis; salicylic acid.

\section{Introduction}

The green algae, Ulva spp., is used worldwide as an important source of food (Michalak and Chojnacka 2009), medicine (Qi et al. 2012), as well as used for waste-water bioremediation (Al-Hafedh et al. 2015). However, Ulva spp. is causative species of the large-scale green tides for its higher growth rate than that of other species under bloom conditions (Zhao et al. 2013). Thus, the study of Ulva species has practical and ecological significance.

Salicylic acid (SA), a phenolic phytohormone, is a well-known signaling molecule and can move free radicals in and out of the cells, tissues, and organs (Kawano et al. 2004), playing a role in the induction of protective mechanisms to withstand biotic or abiotic stresses (Hayat et al. 2010, Vicente and Plasencia 2011). Several studies demonstrate beneficial effects of SA during salinity
(Shakirova et al. 2003, Miura 2014), UVR (Zhuo et al. 2017), high temperatures (Fan et al. 2017, Wang et al. 2017), cold (Miura and Tada 2014) or other environmental factors (Hayat et al. 2010). The effects of exogenous SA on photosynthesis parameters differ depending on the plant species, developmental stage, and SA concentrations (Vicente and Plasencia 2011). SA functions by increasing antioxidant gene expression to alleviate lower saltinduced photosynthetic capacity and high temperature stress in U. prolifera (Fan et al. 2016). Complementary transcriptome and proteome analyses showed that SA alleviated the high-temperature damage by up-regulation of a portion of antioxidant-related proteins (Fan et al. 2017). Additionally, the free movement of SA in cells was regulated by reactive oxygen species (ROS) and $\mathrm{Ca}^{2+}$ binding proteins (Chen et al. 2001). The potential damage of ROS could be counteracted by higher antioxidant

$\overline{\text { Received }} 10$ January 2018, accepted 12 September 2018.

${ }^{+}$Corresponding author; e-mail: liyahe@nbu.edu.cn, xunianjun@nbu.edu.cn

Abbreviations: Car - carotenoids; Chl - chlorophyll; $\mathrm{F}_{\mathrm{v}}{ }^{\prime} / \mathrm{F}_{\mathrm{m}}{ }^{\prime}-$ effective quantum yield of PSII photochemical efficiency; $\mathrm{F}_{\mathrm{v}} / \mathrm{F}_{\mathrm{m}}$ - maximal quantum yield of PSII photochemical efficiency; FM - fresh mass; HL - high light; HSA - 5.0 $\mu \mathrm{g}(\mathrm{SA}) \mathrm{mL}^{-1}$; ML medium light; MSA - $2.5 \mu \mathrm{g}(\mathrm{SA}) \mathrm{mL}^{-1}$; LL - low light; NPQ - nonphotochemical quenching; $P_{\mathrm{M}}$ - maximal photosynthetic rate; $P_{\mathrm{N}}$ - net photosynthetic rate; $P_{\mathrm{G}}-$ gross photosynthetic rate; $R_{\mathrm{D}}$ - dark respiration rate; rETR - relative electron transport rate; RGR - relative growth rate; SA - salicylic acid; $0 \mathrm{SA}-0 \mu \mathrm{g}(\mathrm{SA}) \mathrm{mL}^{-1}$; $\mathrm{SOD}$ - superoxide dismutase.

Acknowledgements: This study was supported by the National Natural Science Foundation of China $(41606129 ; 41876181)$, the Natural Science Foundation of ZhejiangProvince (LY19D060002) and the School Foundation of Ningbo University (XYL18022). This research was also sponsored by the K.C. Wong Magna Fund in Ningbo University. We also thank the comments and suggestions of anonymous reviewers that helped us to improve this manuscript. 
contents and antioxidative enzymes activity, which are associated with higher stress tolerance, such as high salinity (Luo and Liu 2011). Superoxide dismutase (SOD), as a first line of defense against ROS, plays a crucial role in ROS detoxification and diurnal regulation of its activity (Poór et al. 2018).

Light, energy source for photosynthesis, is an important factor that affects the development, reproduction, and antioxidative enzymes activity of marine macroalgae (Han et al. 2003, McDonald 2003, Poór et al. 2018). $U$. prolifera, grown in intertidal ecosystems, has to adapt to wide variations in light intensity, fast and efficient photoprotection is essential for survival. High light upregulated the LHC-related genes in U. prolifera, such as LhcSR and psbS, as well as high level of both LHCSR and PsbS proteins (Mou et al. 2013). Photosynthesis is one of the main targets of environmental stressors. Interactive effects of light and plant growth regulators (PGRs) show that light influences the effects of PGRs on the branching and contents of pigments and total soluble proteins in Gracilaria caudata (Souza and Yokoya 2016). Despite the close relationship between abiotic stresses and hormone regulation in higher plants, the effects of exogenous hormones in algae have not been well studied. In this study, we hypothesized that the effects of light on the physiology and morphogenetic processes of algae might be mediated by SA. Therefore, the objective of this study was to investigate the effects of exogenous SA under three different irradiances on growth rates, pigment contents, chlorophyll (Chl) fluorescence, photosynthesis, and SOD activity.

\section{Materials and methods}

Materials and experimental design: Samples of Ulva prolifera were supplied by Xiangshan Xuwen Seaweed Development Co. Ltd. (China). After being taken to laboratory, they were cleaned and cultured in artificial seawater (salinity 35) enriched with $\mathrm{f} / 2$ medium (without $\mathrm{Si}$, Guillard and Ryther 1962) in an intelligent light incubator ( $G X Z$, Jiangnan Instrument Factory, Ningbo, China) under conditions of $25^{\circ} \mathrm{C}, 70 \mu \mathrm{mol}$ (photon) $\mathrm{m}^{-2} \mathrm{~s}^{-1}$ (12:12-h light/dark period). Because the effects of SA are $\mathrm{pH}$ dependent (Lee et al. 1998), all the cultures were aerated $\left(350 \mathrm{~mL} \mathrm{~min}^{-1}\right)$ with ambient air in order to maintain $\mathrm{pH}$ stable (ca. 8.20-8.25). For each treatment, samples $[\mathrm{ca} .0 .5 \mathrm{~g}$ of fresh mass (FM)] were placed in $500-\mathrm{mL}$ conical flask, each containing $400 \mathrm{~mL}$ of sterile artificial seawater enriched with $\mathrm{f} / 2$ medium without $\mathrm{Si}$. The multi-factorial design comprised three PAR levels [low light (LL): $70 \mu \mathrm{mol}$ (photon) $\mathrm{m}^{-2} \mathrm{~s}^{-1}$; medium light (ML): $160 \mu \mathrm{mol}$ (photon) $\mathrm{m}^{-2} \mathrm{~s}^{-1}$; high light (HL): 400 $\mu \mathrm{mol}\left(\right.$ photon) $\mathrm{m}^{-2} \mathrm{~s}^{-1}$; light:dark $=12: 12 \mathrm{~h}$ ) and three SA concentrations $\left[\mathrm{SA}=0 \mu \mathrm{g} \mathrm{mL} \mathrm{L}^{-1}(0 \mathrm{SA}) ; \mathrm{SA}=2.5 \mu \mathrm{g} \mathrm{mL}^{-1}\right.$

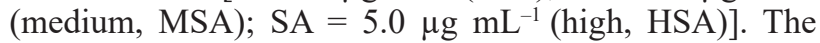
light intensity was selected according to Zhao et al. (2016), while the ML level here was consistent with the PAR of the surface layer of the large-scale algal mats during the green tide in the Qingdao, China. The high SA concentration was determined in our preliminary study (Zhuo et al. 2017).
The treatment combinations were designated as follows:

\begin{tabular}{llll}
\hline $\begin{array}{l}\text { Light } \\
{\left[\mu \mathrm{mol} \mathrm{m}^{-2} \mathrm{~s}^{-1}\right]}\end{array}$ & \multicolumn{2}{l}{ SA concentration $\left[\mu \mathrm{g} \mathrm{mL}^{-1}\right]$} \\
\hline & 0 & 2.5 & 5.0 \\
70 & LLOSA & LLMSA & LLHSA \\
160 & ML0SA & MLMSA & MLHSA \\
400 & HLOSA & HLMSA & HLHSA \\
\hline
\end{tabular}

The fresh masses (FM) were determined every day with the increasing algal biomass removed in order to maintain constant range of biomass density under different culture conditions (Gao et al. 2017). Algal growth rates, pigment contents, Chl fluorescence, photosynthetic oxygen evolution, SOD activity, and total soluble proteins were measured at about 13:00 h after $3 \mathrm{~d}$ of incubation.

Growth rate: Changes in biomass were determined every day, and the relative growth rate of algae $\left(\mathrm{RGR} ; \%\right.$ day $\left.^{-1}\right)$ was calculated as follows: $\mathrm{RGR}=100 \times\left(\ln \mathrm{W}_{\mathrm{t}}-\ln \mathrm{W}_{0}\right) \times \mathrm{T}^{-1}$, where $\mathrm{W}_{\mathrm{t}}$ is the final fresh mass after $\mathrm{T}$ days, $\mathrm{W}_{0}$ is the initial fresh mass (Pickering et al. 1990).

Dark respiration and photosynthetic oxygen evolution rate: Dark respiration $\left(R_{\mathrm{D}}\right)$ and net photosynthetic oxygen evolution $\left(P_{\mathrm{N}}\right)$ were measured as oxygen exchange using a Clark-type oxygen electrode (Hansatech, UK) under different irradiances $[0,20,50,100,200,400$, and 600 $\mu \mathrm{mol}\left(\right.$ photon) $\mathrm{m}^{-2} \mathrm{~s}^{-1}$ at $25^{\circ} \mathrm{C}$, which was controlled by a cooling circulator (Jinghong, Shanghai, China). The light intensity was obtained by altering the distance between the electrode chamber and the light source (LED light, T5, Philips, Netherlands). Approximately $0.01 \mathrm{~g}$ of thalli FM was put into electrode chamber containing $2 \mathrm{~mL}$ of a culture medium. The $R_{\mathrm{D}}$ was measured under darkness by determining the dark $\mathrm{O}_{2}$ consumption. According to Henley (1993) and Chen et al. (2016), the gross photosynthetic oxygen rate $\left(P_{\mathrm{G}}\right)$ was calculated as the sum of the maximum net photosynthetic $\mathrm{O}_{2}$ evolution rate $\left(P_{\mathrm{M}}\right.$, estimated from the net the photosynthesis-irradiation response curves) and $R_{\mathrm{D}}$.

Pigment content: Samples of U. prolifera (ca. $0.02 \mathrm{~g})$ were extracted in $5 \mathrm{~mL}$ of methanol overnight at the $4^{\circ} \mathrm{C}$ in a refrigerator, then the absorption spectrum of the super-natant was obtained by scanning the sample from 250 to $750 \mathrm{~nm}$ with a scanning spectrophotometer (Yuanxi Instrument Co., Ltd, Shanghai). The content of Chl $a$, $\mathrm{Chl} b$, and carotenoids (Car) were calculated according to Lichtenthaler and Wellburn (1983) based on the absorbance of the methanol extracts at 470, 653, $666 \mathrm{~nm}$.

Chl fluorescence parameters of $U$. prolifera grown under different treatments were measured with a pulse modulation fluorometer (Water PAM, Walz, Germany). After dark adaption for $15 \mathrm{~min}$, the induction curves of the thalli were measured for determining the optimal $\left(\mathrm{F}_{\mathrm{v}} / \mathrm{F}_{\mathrm{m}}\right)$ and effective $\left(\mathrm{F}_{\mathrm{v}}{ }^{\prime} / \mathrm{F}_{\mathrm{m}}{ }^{\prime}\right)$ photosynthetic quantum yield. The 
relative electron transport (rETR) and nonphotochemical quenching (NPQ) were obtained from the rapid light curves (RLCs). When the RLCs were measured, the samples were exposed to a light intensity gradient $[0,75$, $114,167,257,379,570,861$, and 1,218 $\mu \mathrm{mol}$ (photon) $\mathrm{m}^{-2} \mathrm{~s}^{-1}$. RLCs were fitted according to the formula: $r E T R=E /\left(a \times P^{2} R^{2}+b \times P A R+c\right)$, where $a, b$, and $c$ are the fitted parameters. The maximal rate of relative electron transport $\left(\mathrm{rETR}_{\max }\right)$, the light-harvesting efficiency $(\alpha)$, and the initial light-saturation point $\left(\mathrm{E}_{\mathrm{k}}\right)$ were calculated from the fitted RLC: $\mathrm{rETR}_{\max }=1 /\left[\mathrm{b}+2(\mathrm{ac})^{1 / 2}\right] ; \alpha=1 / \mathrm{c} ; \mathrm{E}_{\mathrm{k}}=$ $\mathrm{rETR}_{\max } / \alpha$ (Eilers and Peeters 1998). NPQ was attained as follows: $\mathrm{NPQ}=\left(\mathrm{F}_{\mathrm{m}}-\mathrm{F}_{\mathrm{m}}{ }^{\prime}\right) / \mathrm{F}_{\mathrm{m}}{ }^{\prime}, \mathrm{F}_{\mathrm{m}}$ and $\mathrm{F}_{\mathrm{m}}{ }^{\prime}$ are the maximal fluorescence levels from algae after dark adaptation and in light, respectively. Each sample was determined three times, and each treatment had three replications.

SOD activity and total soluble proteins: Samples of $U$. prolifera (ca. 0.1 g FM) were homogenized and extracted with $4 \mathrm{~mL}$ of $50 \mathrm{mmol} \mathrm{L}^{-1}$ phosphate buffer (PBS, $\mathrm{pH}$ 7.8). Then the extracts were centrifuged for $15 \mathrm{~min}$ at $11,000 \times g$ at $4^{\circ} \mathrm{C}$ and the supernatant was used to measure SOD (EC 1.15.1.1) activity based on Giannopolitis and Ries (1977) with some modifications. Reaction mixtures (3 mL) contained $2.7 \mathrm{~mL}$ of $14.5 \mathrm{mmol} \mathrm{L}^{-1}$ methionine, $0.1 \mathrm{~mL}$ of $2.25 \mathrm{mM}$ nitroblue tetrazolium chloride, $0.1 \mathrm{~mL}$

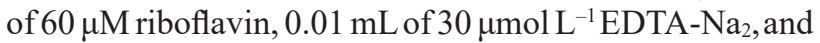
$0.09 \mathrm{~mL}$ of $0.05 \mathrm{~mol} \mathrm{~L}^{-1} \mathrm{PBS}$ (pH 7.8). Enzyme extract od $50 \mu \mathrm{L}$ was added to the reaction mixture, and the reaction was started at $25^{\circ} \mathrm{C}$ and $70 \mu \mathrm{mol}$ (photon) $\mathrm{m}^{-2} \mathrm{~s}^{-1}$ for $20 \mathrm{~min}$, the absorbance was measured at $560 \mathrm{~nm}(U V$ 6100A, Yuanxi Instrument Co., Ltd, Shanghai, China) and the SOD activity was defined as the quantity of SOD required to produce a $50 \%$ reduction of NBT under experimental conditions. The SOD activity was calculated as follows:

SOD total activity $=\left[\left(\mathrm{A}_{\mathrm{CK}}-\mathrm{A}_{\mathrm{E}}\right) \times \mathrm{V}\right] /\left(1 / 2 \mathrm{~A}_{\mathrm{CK}} \times \mathrm{W} \times \mathrm{V}_{\mathrm{t}}\right)$

where $A_{C K}$ and $A_{E}$ represent the absorbance of control and sample, respectively; $\mathrm{V}$ and $\mathrm{V}_{\mathrm{t}}$ are the volume of the sample liquid and the supernatant $(\mathrm{mL}) ; \mathrm{W}$ is the fresh mass of sample $(\mathrm{g})$.

Total soluble protein content was determined by the method of Coomassie Brilliant Blue G-250 dye combination according to Kochert (1978). FM of $0.1 \mathrm{~g}$ was homogenized and extracted with $4 \mathrm{~mL}$ of $50 \mathrm{mmol} \mathrm{L}^{-1}$ PBS ( $\mathrm{pH} 7.8$ ). The extracts were centrifuged for $15 \mathrm{~min}$ at $11,000 \times g$ at $4^{\circ} \mathrm{C}$. The reaction solution included $50 \mu \mathrm{l}$ of supernatant, $50 \mu \mathrm{L}$ of $50 \mathrm{mmol} \mathrm{L}^{-1} \mathrm{PBS}(\mathrm{pH}$ $7.8)$; the absorbance of the reaction solution at $595 \mathrm{~nm}$ was recorded (UV-6100A, Yuanxi Instrument Co., Ltd, Shanghai, China). Bovine albumin (BSA) was used as a standard.

Data analysis: Origin 7.0 and SPSS 18.0 were used for data processing and statistical analysis one-way $(A N O V A)$ and two-way analysis of variance (ANOV2A) and the Tukey's test were used to analyze differences between treatments. Significance was set at $p \leq 0.05$ for all statistical analyses. All the data were expressed as means $\pm \operatorname{SD}(n=3)$.

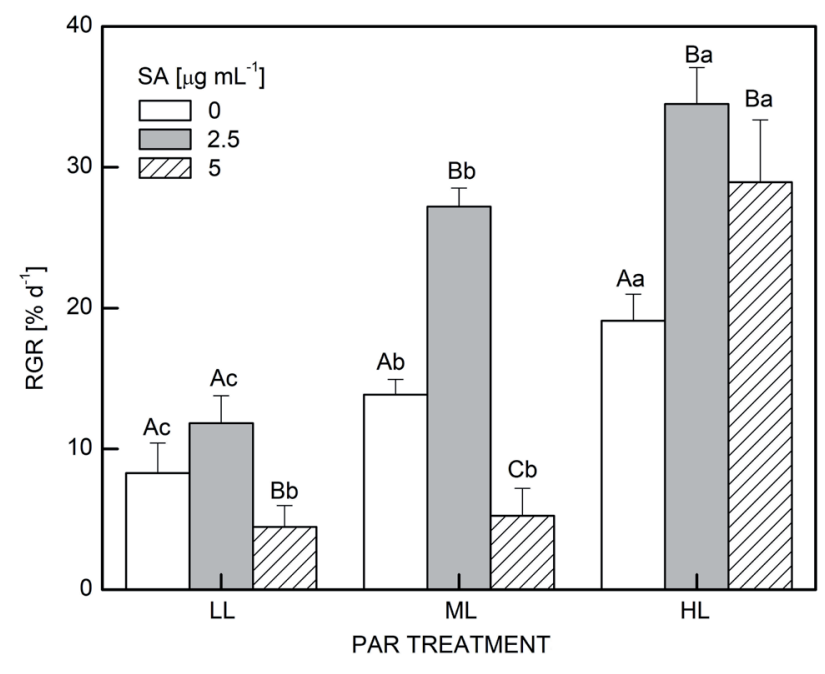

Fig. 1. The relative growth rate (RGR) of Ulva prolifera under different treatments. Different capital letters indicated significant difference between different salicylic acid (SA) concentrations at the same light, and different small letters indicated significant difference between different light treatments at the same SA concentration. HL - high light, ML - medium light, LL - low light.

\section{Results}

RGR: The RGR of $U$. prolifera increased with the in-crease of light, no matter with or without SA. Under the three light levels, the highest RGR was observed in the presence of MSA $\left[2.5 \mu \mathrm{g}(\mathrm{SA}) \mathrm{mL}^{-1}\right]$, which was 81 and $96 \%$ higher than that in the treatment without SA under HL and ML, respectively. The RGR significantly decreased by the HSA $\left[5.0 \mu \mathrm{g}(\mathrm{SA}) \mathrm{mL}^{-1}\right]$ under the ML and LL conditions (Fig. 1). Two-way ANOVA showed that SA and light had an interactive effect, and both SA and light exerted significant effect on the RGR of $U$. prolifera $\left(\mathrm{F}_{2,2}=21.64, p<0.001\right.$; Table 1S, supplement).

Photosynthetic oxygen evolution rate: Results showed that no interactive effect occurred between SA and light, but both SA and light exerted significant effect on photosynthetic performance of $U$. prolifera (Tables 1, 1S). Under the three light levels, the $P_{\mathrm{N}}, P_{\mathrm{M}}$, and $P_{\mathrm{G}}$ significantly decreased by SA, and there was no significant difference between the MSA and LSA treatments. The similar trend was observed for $R_{\mathrm{D}}$. However, under HL conditions, there was significant difference between the MSA and LSA treatments, and there were no significant effects of light on $R_{\mathrm{D}}$ observed (Table 1), and the interactive effects of SA and light were also indifferent (Table $1 \mathrm{~S}$ ).

Pigment content: With the increase of the light, Chl $a$ and $\mathrm{Chl} b$ contents decreased, but the ratio of $\mathrm{Chl} a / b$ increased, although there was no significant difference between the ML and HL. The presence of SA enhanced the Chl $a$ content, especially under the LL conditions, with the Chl $a$ content increasing from $1.14 \mathrm{mg} \mathrm{g}^{-1}$ (0SA) to 1.61 $\mathrm{mg} \mathrm{g}^{-1}$ (HSA). The carotenoids (Car) content increased with the increase of light level, especially in the absence 
Table 1. The net photosynthetic oxygen rate $\left(P_{\mathrm{N}}\right)$, maximal $\left(P_{\mathrm{M}}\right)$, gross photosynthetic oxygen rate $\left(P_{\mathrm{G}}\right)$, and dark respiration rate $\left(R_{\mathrm{D}}\right)$ of Ulva prolifera grown under the different light intensity. Different capital letters indicated significant difference between different salicylic acid (SA) concentrations at the same light, and different small letters indicated significant difference between different light treatments at the same SA concentration. Treatment abbreviations are explained in Abbreviations.

\begin{tabular}{lllll}
\hline Treatment & $P_{\mathrm{N}}$ & $P_{\mathrm{M}}$ & $P_{\mathrm{G}}$ & $R_{\mathrm{D}}$ \\
\hline LL0SA & $224.3 \pm 25.2^{\mathrm{Aa}}$ & $434.6 \pm 17.8^{\mathrm{Aa}}$ & $502.4 \pm 26.5^{\mathrm{Aa}}$ & $73.4 \pm 4.3^{\mathrm{Ab}}$ \\
LLMSA & $63.5 \pm 0.2^{\mathrm{Bb}}$ & $230.9 \pm 50.2^{\mathrm{Ba}}$ & $256.0 \pm 65.8^{\mathrm{Bb}}$ & $30.3 \pm 17.8^{\mathrm{Bab}}$ \\
LLHSA & $67.5 \pm 10.8^{\mathrm{Bb}}$ & $243.8 \pm 12.1^{\mathrm{Ba}}$ & $268.9 \pm 13.0^{\mathrm{Bc}}$ & $38.9 \pm 5.9^{\mathrm{Ba}}$ \\
ML0SA & $253.6 \pm 28.5^{\mathrm{Aa}}$ & $360.7 \pm 46.8^{\mathrm{Ab}}$ & $445.9 \pm 47.6^{\mathrm{Aa}}$ & $92.3 \pm 1.2^{\mathrm{Aa}}$ \\
MLMSA & $113.3 \pm 5.7^{\mathrm{Ba}}$ & $191.6 \pm 24.1^{\mathrm{Ba}}$ & $225.2 \pm 27.1^{\mathrm{Ba}}$ & $39.2 \pm 3.9^{\mathrm{Bb}}$ \\
MLHSA & $121.1 \pm 4.7^{\mathrm{Ba}}$ & $213.7 \pm 1.56^{\mathrm{Bb}}$ & $231.6 \pm 3.5^{\mathrm{Bb}}$ & $33.7 \pm 6.5^{\mathrm{Ba}}$ \\
HLOSA & $242.1 \pm 31.7^{\mathrm{Aa}}$ & $320.2 \pm 28.9^{\mathrm{Ab}}$ & $397.0 \pm 30.9^{\mathrm{Aa}}$ & $89.2 \pm 14.5^{\mathrm{Aab}}$ \\
HLMSA & $144.4 \pm 7.0^{\mathrm{Ba}}$ & $179.7 \pm 30.1^{\mathrm{Ba}}$ & $224.2 \pm 36.2^{\mathrm{Ba}}$ & $64.9 \pm 1.4^{\mathrm{Ba}}$ \\
HLHSA & $159.2 \pm 26.6^{\mathrm{Ba}}$ & $188.8 \pm 29.8^{\mathrm{Bb}}$ & $210.5 \pm 27.7^{\mathrm{Ba}}$ & $35.4 \pm 4.5^{\mathrm{Ca}}$ \\
\hline
\end{tabular}

Table 2. Mean concentration of photosynthetic pigments: Chl $a$, Chl $b$, carotenoids (Car), the ratio between Chl $a$ and Chl $b$ (Chl $a / b)$, and the ratio between $\mathrm{Chl} a$ and $\mathrm{Car}(\mathrm{Chl} a / \mathrm{Car})$ of Ulva prolifera under different treatments. Values are means ( $\pm \mathrm{SD})$. Contents are in $\left[\mathrm{mg} \mathrm{g}^{-1}(\mathrm{FM})\right]$ for each pigment. Different capital letters indicated significant difference between different SA concentrations at the same light, and different small letters indicated significant difference between different light treatments at the same salicylic acid (SA) concentration. Treatment abbreviations are explained in Abbreviations

\begin{tabular}{llllll}
\hline Treatment & Chl $a$ & Chl $b$ & Car & Chl $a / b$ & Chl $a /$ Car \\
\hline LL0SA & $1.15 \pm 0.07^{\mathrm{Ab}}$ & $0.87 \pm 0.04^{\mathrm{Ab}}$ & $0.04 \pm 0.01^{\mathrm{Aa}}$ & $1.32 \pm 0.016^{\mathrm{Ab}}$ & $31.47 \pm 8.20^{\mathrm{Aa}}$ \\
LLMSA & $1.45 \pm 0.26^{\mathrm{Bc}}$ & $1.11 \pm 0.10^{\mathrm{Acb}}$ & $0.27 \pm 0.07^{\mathrm{Ba}}$ & $1.31 \pm 0.16^{\mathrm{Bc}}$ & $5.49 \pm 0.61^{\mathrm{Ba}}$ \\
LLHSA & $1.75 \pm 0.37^{\mathrm{Bb}}$ & $1.21 \pm 0.28^{\mathrm{ABb}}$ & $0.43 \pm 0.09^{\mathrm{Ca}}$ & $1.45 \pm 0.03^{\mathrm{Cb}}$ & $4.09 \pm 0.02^{\mathrm{Cab}}$ \\
ML0SA & $1.12 \pm 0.15^{\mathrm{Ab}}$ & $0.76 \pm 0.09^{\mathrm{ABb}}$ & $0.08 \pm 0.01^{\mathrm{Ab}}$ & $1.47 \pm 0.02^{\mathrm{Aa}}$ & $13.31 \pm 1.00^{\mathrm{Ab}}$ \\
MLMSA & $1.14 \pm 0.41^{\mathrm{Ab}}$ & $0.86 \pm 0.25^{\mathrm{Ba}}$ & $0.22 \pm 0.08^{\mathrm{Ba}}$ & $1.32 \pm 0.09^{\mathrm{Ab}}$ & $5.25 \pm 0.09^{\mathrm{Ba}}$ \\
MLHSA & $1.27 \pm 0.16^{\mathrm{Bb}}$ & $0.87 \pm 0.13^{\mathrm{Ab}}$ & $0.31 \pm 0.03^{\mathrm{Cb}}$ & $1.47 \pm 0.03^{\mathrm{Bb}}$ & $4.20 \pm 0.15^{\mathrm{Cb}}$ \\
HLOSA & $0.84 \pm 0.06^{\mathrm{Aa}}$ & $0.57 \pm 0.05^{\mathrm{Aa}}$ & $0.15 \pm 0.05^{\mathrm{Ac}}$ & $1.49 \pm 0.05^{\mathrm{Aa}}$ & $6.10 \pm 1.64^{\mathrm{Ac}}$ \\
HLMSA & $0.93 \pm 0.17^{\mathrm{Ba}}$ & $0.59 \pm 0.12^{\mathrm{Ba}}$ & $0.25 \pm 0.07^{\mathrm{Ba}}$ & $1.57 \pm 0.03^{\mathrm{Ba}}$ & $3.70 \pm 0.32^{\mathrm{Bb}}$ \\
HLHSA & $0.95 \pm 0.24^{\mathrm{Aa}}$ & $0.59 \pm 0.16^{\mathrm{Aa}}$ & $0.27 \pm 0.03^{\mathrm{Bb}}$ & $1.59 \pm 0.02^{\mathrm{Ca}}$ & $3.53 \pm 0.44^{\mathrm{Ba}}$ \\
\hline
\end{tabular}

of SA, and this value was significantly enhanced by SA under the LL conditions (Table 2). The interactive effects of SA and light on the Car were significant $\left(\mathrm{F}_{2,2}=4.07\right.$; $p=0.010)$.

Chl fluorescence: In the absence of $S A$, the $F_{v} / F_{m}$ of $U$. prolifera significantly decreased by $\mathrm{HL}$, but no differences were observed between the ML and LL. Under the three light levels, the $F_{v} / F_{m}$ was enhanced by $S A$, except for the HSA [5.0 $\mu \mathrm{g}(\mathrm{SA}) \mathrm{mL}^{-1}$ ] under LL treatment (Fig. $2 A$ ). For the $\mathrm{F}_{\mathrm{v}}{ }^{\prime} / \mathrm{F}_{\mathrm{m}}{ }^{\prime}$, different trends were observed: (1) under the $\mathrm{HL}$ or $\mathrm{LL}$, the maximum values were observed at MSA treatment; (2) under the ML level, this value was enhanced both by MSA and HSA; (3) $\mathrm{F}_{\mathrm{v}}{ }^{\prime} / \mathrm{F}_{\mathrm{m}}{ }^{\prime}$ decreased with the increase of light level under all SA concentrations (Fig. 2B).

In view of the RLCs, significant differences in the initial light-saturation point $\left(\mathrm{E}_{\mathrm{k}}\right)$, maximal rate of rETR $\left(\mathrm{rETR}_{\max }\right)$, and apparent photosynthetic efficiency $(\alpha)$ between different treatments were observed (Table 3, Fig. 3). With the light increasing from 70 to 400 $\mu$ mol(photon) $\mathrm{m}^{-2} \mathrm{~s}^{-1}$, the $\mathrm{rETR}_{\max }$ decreased, but was enhanced by SA, especially under the ML and

HL conditions. However, for the HL treatment [400 $\mu$ mol(photon) $\mathrm{m}^{-2} \mathrm{~s}^{-1}$, compared to MSA treatment, the inhibiting effects of HSA were observed (Fig. 3C).

Nonphotochemical quenching (NPQ) extracted from recorded RLCs of rETR indicated variations with respect to the changes in irradiance. In the absence of SA, The NPQ of thalli grown at HL was higher than that grown under LL conditions at each irradiance, but this value was reduced by SA (Fig. 4).

Activity of superoxide dismutase (SOD) and the total soluble protein: Under the HL or LL conditions, the presence of MSA significantly down-regulated the SOD activity, while it was enhanced by HSA, especially under LL. After HSA treatment, the SOD activity increased with the increase of light level, although there was no significant effect of light level observed in the absence of SA (Fig. 5A).

HL lowered the total soluble proteins in the absence of SA. There were no significant effects of SA on the total soluble proteins under LL and ML levels, but under HL, this value increased by SA, although the difference was insignificant (Fig. 5B). 


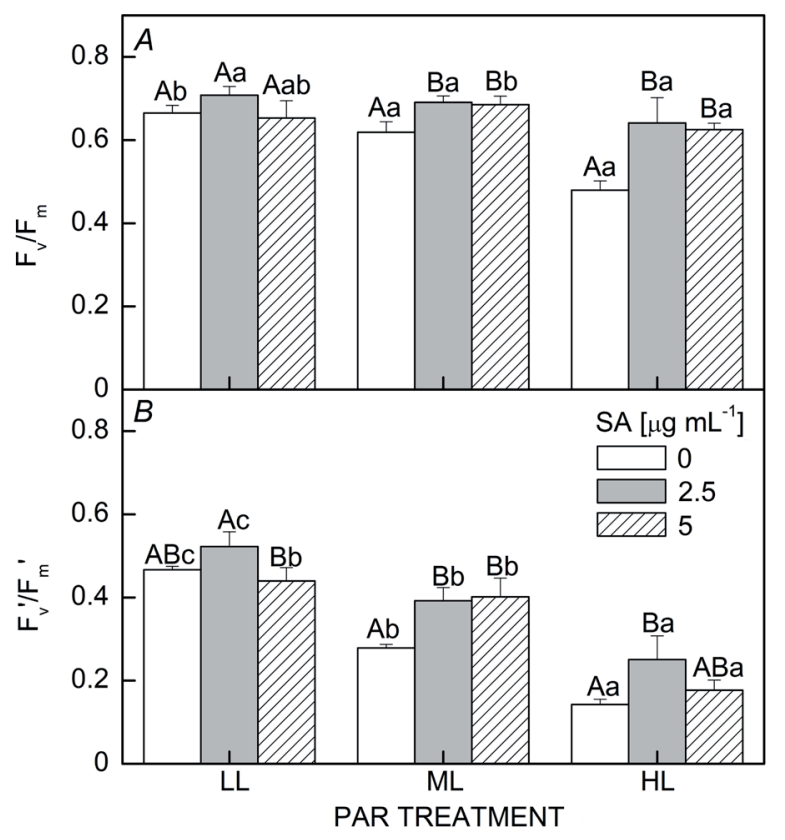

Fig. 2. The maximal $\left(\mathrm{F}_{\mathrm{v}} / \mathrm{F}_{\mathrm{m}} ; A\right)$ and effective $\left(\mathrm{F}_{\mathrm{v}}{ }^{\prime} / \mathrm{F}_{\mathrm{m}}{ }^{\prime} ; B\right)$ photochemical efficiency of Ulva prolifera under different treatments. Different capital letters indicated significant difference between different salicylic acid (SA) concentrations at the same light, and different small letters indicated significant difference between different light treatments at the same SA concentration. HL high light, $\mathrm{ML}$ - medium light, LL - low light.

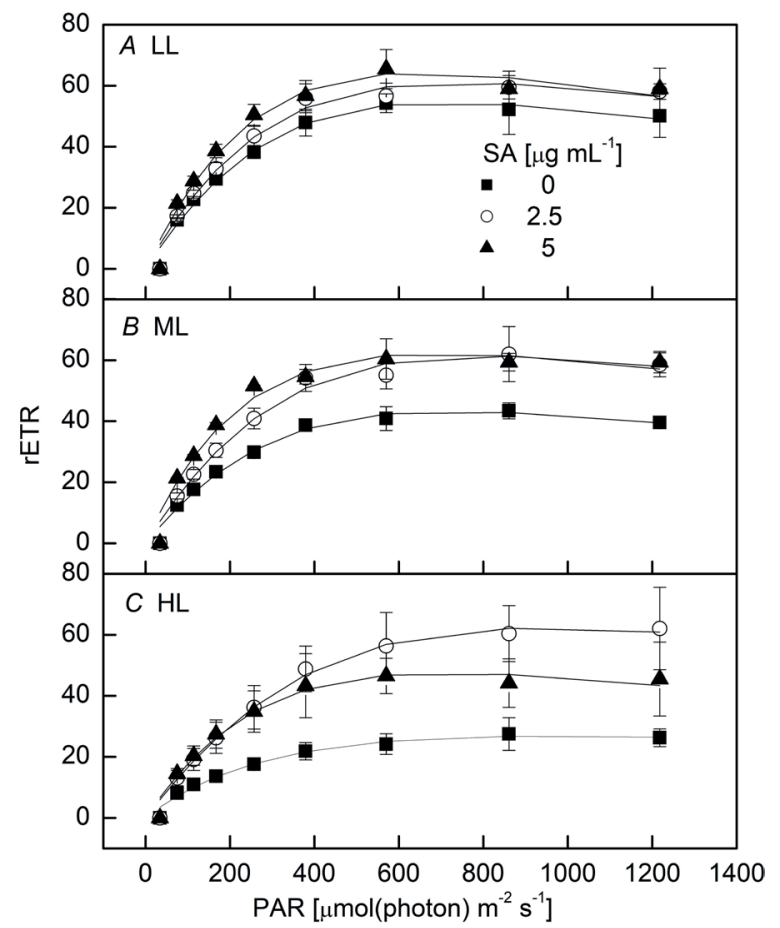

Fig. 3. The relative electron transport rates (rETR) of Ulva prolifera under different treatments. Different capital letters indicated significant difference between different salicylic acid (SA) concentrations at the same light, and different small letters indicated significant difference between different light treatments at the same SA concentration.HL - high light, ML - medium light, $\mathrm{LL}$ - low light.

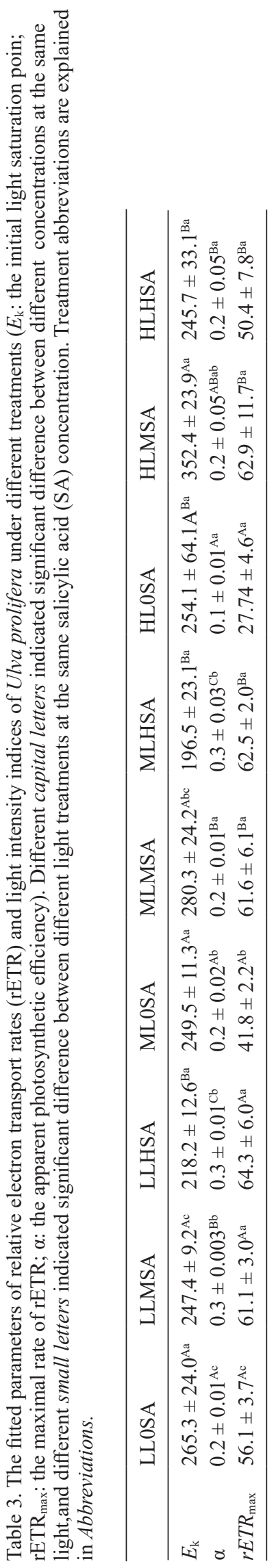




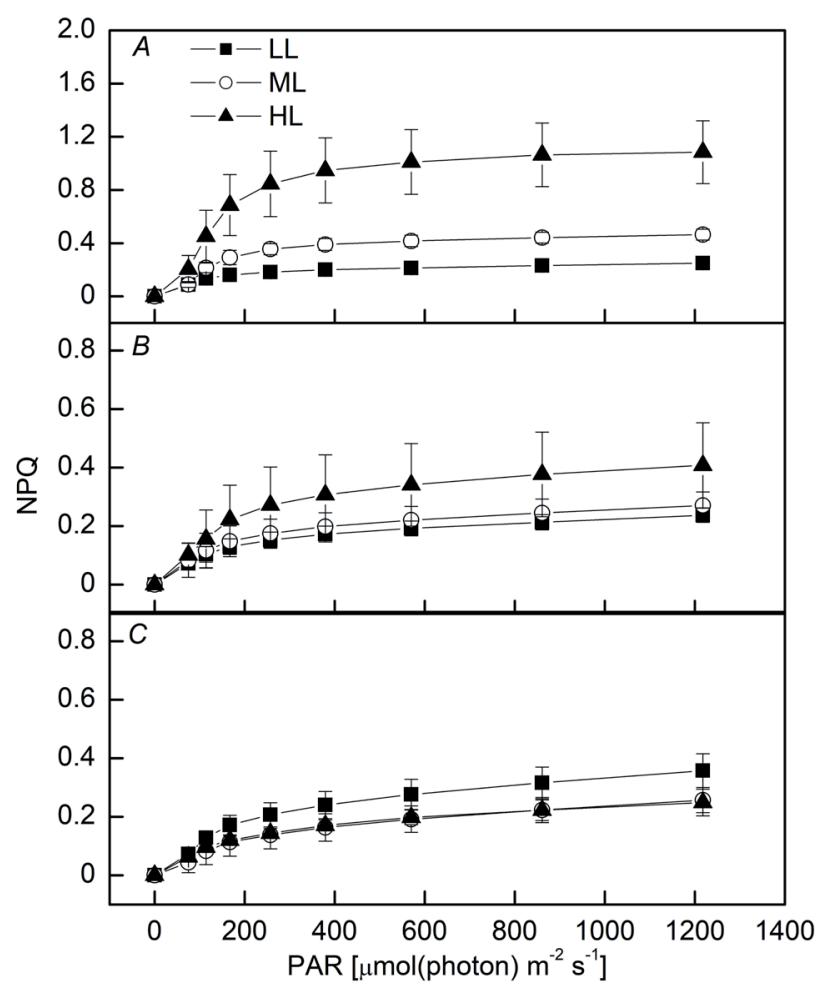

Fig. 4. Nonphotochemical quenching (NPQ; $A: \mathrm{SA}=0 ; B: \mathrm{SA}$ $=2.5 \mu \mathrm{g} \mathrm{mL} L^{-1} ; C: \mathrm{SA}=5 \mu \mathrm{g} \mathrm{mL}^{-1}$ ) a function of increasing irradiances, obtained from culture three days under different acclimation to each conditions. Values are mean $\pm \mathrm{SD}(n=3)$. Different capital letters indicated significant difference between different salicylic acid (SA) concentrations at the same light, and different small letters indicated significant difference between different light treatments at the same SA concentration.HL - high light, $\mathrm{ML}$ - medium light, $\mathrm{LL}$ - low light.

\section{Discussion}

Light is essential for all the photosynthetic organisms (McDonald 2003) and the responses to light changes are species-specific. Early studies showed that U. prolifera has a strong photosynthetic plasticity to adapt to complex environments, including changing in pigment components, energy quenching, and energy redistribution between growth and reproduction (Han et al. 2003, Zhao et al. 2016). In the present study, with the increase of light, the growth of $U$. prolifera was significantly enhanced, even under $400 \mu \mathrm{mol}$ (photon) $\mathrm{m}^{-2} \mathrm{~s}^{-1}$, higher growth rate was also observed, as well as the higher Car contents and higher NPQ, showing more efficacious photoprotection. The decreased Chl concentration with the increase of light was also observed. Chl content, which appears to be related to the content of light-harvesting complex proteins and the extent of grana formation (Anderson et al. 1973), was the most important for achieving the maximum potential photosynthesis. Under LL conditions, U. prolifera needed more Chl $a$ to capture light in order to keep higher photosynthetic rate, but under HL conditions, the synthesis of photosynthetic pigments ( $\mathrm{Chl} a$ ) was reduced to decrease the excitation pressure on the reaction

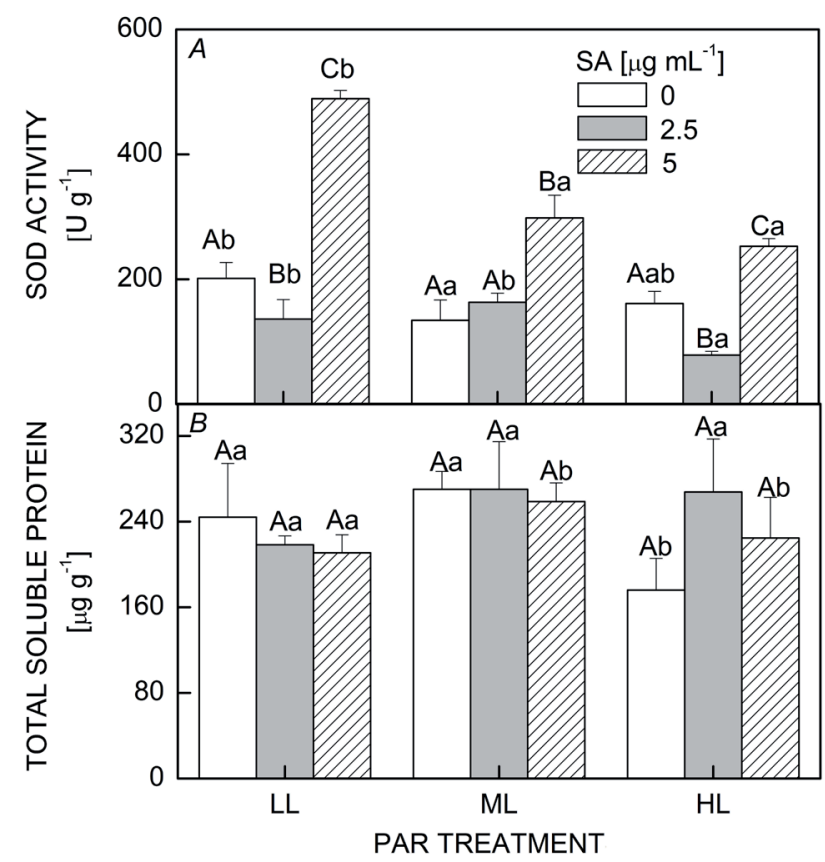

Fig. 5. The SOD activity $(A)$ and otal soluble protein $(B)$ of Ulva prolifera under different treatments. Different capital letters indicated significant difference between different salicylic acid (SA) concentrations at the same light, and different small letters indicated significant difference between different light treatments at the same SA concentration. HL - high light, ML - medium light, LL - low light.

center of PSII, which was also found in other studies (Wang et al. 2016). These results suggested the higher photosynthetic plasticity and tolerance of $U$. prolifera to light. This could be further demonstrated by the results of the Chl fluorescence. This study showed that the value of $F_{v} / F_{m}$ and $F_{v}{ }^{\prime} / F_{m}{ }^{\prime}$ for LL-grown thalli was significantly higher than those of HL-grown thalli. The HL-grown thalli showed higher NPQ, especially in the absence of SA, showing the efficacious photoprotection in $U$. prolifera. The results were in accordance with the findings related to the concentrations of Chl $a$ and $\mathrm{Chl} b$.

The RLCs could reflect similar results with higher $\mathrm{rERT}_{\text {max }}$ observed under LL conditions. It could be proposed tentatively that the HL-grown thalli might experience greater light-induced damage, which could reduce their relative photosynthetic efficiency. Earlier studies showed that the HL up-regulated the expression of LhcSR, PsbS, and Car, which played a role in photoprotection (Hsu and Lee 2012, Zhang et al. 2013, Guan et al. 2016). Therefore, this study reported that the photochemical energy conversion and adaptive regulatory mechanisms of the thalli grown under HL conditions still functioned and PSII was not damaged severely.

As a plant hormone, SA is considered to be an important signaling molecule in response to environmental stresses, such as salinity, cold, heat, and UV (Hayat et al. 2010, Wang et al. 2017, Zhuo et al. 2017). For plants, the effects of exogenous SA on growth, development, seed germination, fruit yield, and its responses to environmental 
stresses have been studied extensively (Hayat et al. 2010). For algae, the positive effects of SA had been reported in Chlorella vulgaris (Czerpak et al. 2002) and Gracilariopsis lemaneiformis (Wang et al. 2017). In this study, the promoting effects of low concentration SA on the growth were significant, the higher SA-induced growth (ca. 95\% increase) was observed under ML conditions [160 $\mu \mathrm{mol}($ photon $) \mathrm{m}^{-2} \mathrm{~s}^{-1}$. The increased Car content by SA could alleviate the damage induced by HL, and the increase of pigment contents was found in the other study (Uzunova and Popova 2000). The inhibiting effects of SA on the dark respiration might occur in order to prevent electron flow from the substrate dehydrogenases to the UQ pool (Vicente and Plasencia 2011), and the decreased activity of Rubisco and phosphoenolpyruvate carboxylase (PEPC) under high SA concentration contributed to the inhibiting effects of high concentration SA on the algal RGR (Pancheva et al.1996). Previous study showed that the SA functions largely by increasing gene expression of Mn-SOD to alleviate high temperature stress in $U$. prolifera (Fan et al. 2016), as well as the $\mathrm{Ca}^{2+}$-binding proteins, which affected the movement of SA in cells (Chen and Kuc 1999). The increased SOD activity at the high SA concentration $\left(5 \mu \mathrm{g} \mathrm{mL}^{-1}\right)$ was observed, which contributed to the higher $\mathrm{H}_{2} \mathrm{O}_{2}$ induced by SA (Janda et al. 2014).

In conclusion, our results indicated that the growth rates of $U$. prolifera were affected by SA and light. Moreover, the photochemical efficiency and carbon fixation showed different responses to SA; the reasons need to be further studied. The effects of SA were concentration-dependent; a controlled SA concentration is crucial to alleviate the damage induced by environmental factors.

\section{References}

Al-Hafedh Y.S., Alam A., Buschmann A.H.: Bioremediation potential, growth and biomass yield of the green seaweed, Ulva lactuca in an integrated marine aquaculture system at the Red Sea coast of Saudi Arabia at different stocking densities and effluent flow rates. - Rev. Aquacult. 7: 161-171, 2015.

Anderson J.M., Goodchild D.J., Boardman N.K.: Composition of the photosystems and chloroplast structure in extreme shade plants. - Biochim. Biophys. Acta 325: 573-585, 1973.

Chen B.B., Zou D.H., Ma J.H.: Interactive effects of elevated $\mathrm{CO}_{2}$ and nitrogen-phosphorus supply on the physiological properties of Pyropia haitanensis (Bangiales, Rhodophyta). J. Appl. Phycol. 28: 1235-1243, 2016.

Chen H.J., Hou W.C., Kuć J., Lin Y.H.: $\mathrm{Ca}^{2+}$-dependent and $\mathrm{Ca}^{2+}$ independent excretion modes of salicylic acid in tobacco cell suspension culture. - J. Exp. Bot. 52: 1219-1226, 2001.

Chen H.J., Kuc J.: $\mathrm{Ca}^{2+}$-dependent excretion of salicylic acid in tobacco cell suspension culture. - Botanic. Bul. Acad. Sinica 40: 267-273,1999.

Czerpak R., Bajguz A., Gromek M.: Activity of salicylic acid on the growth and biochemism of Chlorella vulgaris Beijerinck. - Acta Physiol. Plant. 24: 45-52, 2002.

Eilers P.H.C., Peeters J.C.H.: A model for the relationship between light intensity and the rate of photosynthesis in phytoplankton. - Ecol. Model. 42: 199-215, 1998.

Fan M.H., Sun X., Xu N.J. et al.: cDNA cloning, characterization and expression analysis of manganese superoxide dismutase in Ulva prolifera. - J. Appl. Phycol. 28: 1391-1401, 2016
Fan M.H., Sun X., Xu N.J. et al.: Integration of deep transcriptome and proteome analyses of salicylic acid regulation high temperature tress in Ulva prolifera. - Sci. Rep. 7: 11052, 2017.

Gao G., Clare A.S., Rose C. et al.: Eutrophication and warmingdriven green tides (Ulva rigida) are predicted to increase under future climate change scenarios. - Mar. Pollut. Bull. 114: 439-447, 2017

Giannopolitis C.N., Ries S.K.: Superoxide dismutases I. Occurrence in higher plants. - Plant Physiol. 59: 309-314, 1977.

Guan Z., Mou S.L., Zhang X.W. et al.: Identification and expression analysis of four light harvesting-like (Lhc) genes associated with light and desiccation stress in Ulva linza. - J. Exp. Mar. Biol. Ecol. 478: 10-15, 2016.

Guillard R.R.L., Ryther J.H.: Studies of marine planktonic diatoms: I. Cyclotella Nana Hustedt, and Detonula confervacea (CLEVE) Gran. - Can. J. Microbiol. 8: 229-239, 1962.

Hayat Q., Hayat S., Irfan M. et al.: Effect of exogenous salicylic acid under changing environment: A review. - Environ. Exp. Bot. 68: 14-25, 2010

Han T., Han Y.S., Kim K.Y. et al.: Influences of light and UV-B on growth and sporulation of the green alga Ulva pertusa Kjellman. - J. Exp. Mar. Biol. Ecol. 290: 115-131, 2003.

Henley W.J.: Measurment and interpretation of photosynthetic light-response curves algae in the context of photoinhibition and diel changes. - J. Phycol. 29: 729-739, 1993.

Hsu Y.T., Lee T.M.: Modulation of gene expression of carotene biosynthesis-related protein by photosynthetic electron transport for the acclimation of intertidal macroalga Ulva fasciata to hypersalinity and excess light. - Physiol. Plantarum 144: 225-237, 2012.

Janda T., Gondor O.K., Yordanova R. et al.: Salicylic acid and photosynthesis: signalling and effects. - Acta Physiol. Plant. 36: 2537-2546, 2014.

Kawano T., Furuichi T., Muto S.: Controlled free salicylic acid levels and corresponding signaling mechanisms in plants. Plant Biotechnol. 21: 319-335, 2004.

Kochert G.: Protein determination by dye binding. - In: Hellebust J.A., Craigie J.S. (ed.): Handbook of Phycological Methods: Physiological and Biochemical Methods. Pp. 91-93. Cambridge University Press, Cambridge 1978.

Lee J.S.: The mechanism of stomatal closing by salicylic acid in Commelina communis L. - J. Plant Biol. 41: 97-102, 1998.

Lichtenthaler H.K., Wellburn A.R.: Determinations of total carotenoids and chlorophylls $\mathrm{a}$ and $\mathrm{b}$ of leaf extracts in different solvents. - Biochem. Soc. Trans. 11: 591-592, 1983.

Luo M.B., Liu F.: Salinity-induced oxidative stress and regulation of antioxidant defense system in the marine macroalga Ulva prolifera. - J. Exp. Mar. Biol. Ecol. 409: 223-228, 2011

Michalak I., Chojnacka K.: Edible macroalga Ulva prolifera as microelemental feed supplement for livestock: the fundamental assumptions of the production method. - World J Microbiol. Biotechnol. 25: 997-1005, 2009.

McDonald M.S.: Photobiology of Higher Plants. Pp. 368. John Wiley \& Sons, Hoboken, New Jersey 2003.

Miura K., Tada Y.: Regulation of water, salinity, and cold stress responses by salicylic acid. - Front. Plant Sci. 5: 4, 2014.

Mou S., Zhang X., Dong M. et al.: Photoprotection in the green tidal alga Ulva prolifera: role of LHCSR and PsbS proteins in response to high light stress. - Plant Biol. 15: 1033-1039, 2013.

Pancheva T.V., Popova L.P., Uzunova A.N. et al.: Effects of salicylic acid on growth and photosynthesis in barley plants. - J. Plant Physiol. 149: 57-63, 1996.

Pickering T.D., Gordon M.E., Tong L.J.: Seasonal growth, 
density, reproductive phenology and agar quality of Gracilaria sordida (Gracilariales, Rhodophyta) at Molkomoko Inlet, New Zealand. - Hydrobiologia 204/205: 253-262, 1990.

Poór P., Ördög A., Czékus Z. et al.: Regulation of the key antioxidant enzymes by developmetal processes and environmental stress in the dark. - Biol. Plantarum 62: 201210,2018 .

Qi H., Huang L., Liu X. et al.: Antihyperlipidemic activity of high sulfate content derivative of polysaccharide extracted from Ulva pertusa (Chlorophyta). - Carbohyd. Polym. 87: 1637-1640, 2012.

Shakirova F.M., Sakhabutdinova A.R., Bezrukova M.V. et al.: Changes in the hormonal status of wheat seedlings induced by salicylic acid and salinity. - Plant Sci. 164: 317-322, 2003.

Souza J.M.C., Yokoya N.S.: Effects of cytokinins on physiological and biochemical responses of the agar-producing red alga Gracilaria caudata (Gracilariales, Rhodophyta). - J. Appl. Phycol. 28: 3491-3499, 2016.

Uzunova A.N., Popova L.P.: Effect of salicylic acid on leaf anatomy and chloroplast ultrastructure of barley plants. Photosynthetica 38: 243-250, 2000.

Vicente M.R.S., Plasencia J.: Salicylic acid beyond defence: its role in plant growth and development. - J. Exp. Bot. 62: 3321-
3338, 2011.

Wang Y., Qu T., Zhao X. et al.: A comparative study of the photosynthetic capacity in two green tide macroalgae using chlorophyll fluorescence. - SpringerPlus 5: 775, 2016

Wang F.J., Wang C.B., Zou T.L. et al.: Comparative transcriptional profiling of Gracilariopsis lemaneiformis in response to salicylic acid- and methyl jasmonate-mediated heat resistance. - PLoS ONE 12: e0176531, 2017.

Zhao J., Jiang P., Liu Z.Y. et al.: The Yellow Sea green tides were dominated by one species, Ulva (Enteromorpha) prolifera, from 2007 to 2011. - Chin. Sci. Bull. 58: 2298-2302, 2013.

Zhao X.Y., Tang X.X., Zhang H.X. et al.: Photosynthetic adaptation strategy of Ulva prolifera floating on the sea surface to environmental changes. - Plant Physiol. Bioch. 107: 116-125, 2016.

Zhang X.W., Ye N.H., Mou S.L. et al.: Occurrence of the PsbS and LhcSR products in the green alga Ulva linza and their correlation with excitation pressure. - Plant Physiol. Bioch. 70: 336-341, 2013.

Zhuo P.L., Zhong J.L., Wang D. et al.: Effect of exogenous salicylic acid and ultraviolet radiation on Ulva prolifera under different light conditions. - Chin. J. Appl. Ecol. 28: 19771983, 2017. [In Chinese]

(C) The authors. This is an open access article distributed under the terms of the Creative Commons BY-NC-ND Licence. 